\title{
Treatment of respiratory failure following chest injuries
}

\author{
M. AmbiavagAR \\ Intensive Care Unit and Clinical Pharmacology Unit (University of Liverpool), \\ Whiston Hospital, Prescot, Lancashire
}

WITH the growth of industry and the increasing use of high velocity vehicles on the roads, chest injuries are becoming common enough to constitute a major problem in civilian practice. London (1963) described ninety-three patients with chest trauma admitted to the Birmingham accident hospital in 1 year, threequarters of them with multiple injuries. The injury may be immediately fatal but a large proportion of those that reach hospital alive can be saved (Table 1).

TABLE 1

Ventilator treatment of the crushed chest

\begin{tabular}{lcc}
\hline \multicolumn{1}{c}{ Reference } & $\begin{array}{c}\text { No. of } \\
\text { patients } \\
\text { treated }\end{array}$ & $\begin{array}{c}\text { No. } \\
\text { survived }\end{array}$ \\
\hline Avery, Morch \& Benson (1956) & 1 & 1 \\
Boyle, Gallie \& Murray (1957) & 1 & 0 \\
Johansson \& Silander (1959) & 12 & 7 \\
Griffiths (1960) & 6 & 3 \\
Fairley \& Chambers (1960) & 8 & 7 \\
Windsor \& Dwyer (1961) & 8 & 7 \\
Griffiths (1963) & 38 & 33 \\
Gothman \& Hogman (1964) & 17 & 11 \\
Whitwam \& Norman (1964) & 9 & 6 \\
Williams \& Zeitlin (1965) & 5 & 4 \\
Lloyd, Crampton-Smith \& O'Connor & 33 & 22 \\
(1965) & 27 & 16 \\
Nordlund (1966) & 14 & 9 \\
Ambiavagar et al. (1966) & & \\
\hline
\end{tabular}

Respiratory failure may be obvious right from the outset after a stove-in-chest, for example, but can develop insidiously over a period of hours or days when the injury is less dramatic, and it is wise to work on the assumption that respiratory failure may follow any chest injury, however trivial. Surgically treatable conditions such as a haemothorax which causes tamponade of the lung and may subsequently resolve and organize leading to permanent disability, or a pneumothorax that reduces ventilatory capacity and interferes with gas exchange by increasing the VA/Q ratio (Jacobeus, 1938; Cournand \& Richards, 1941; Gaensler, Watson \& Patton, 1953), are clearly understood and effectively treated.

In contrast, the physiological derangements that most commonly lead to respiratory failure are little studied and less effectively treated. Barrett (1960) vividly described their natural history when he said 'patients with multiple injuries, including a stove-inchest, often die without obvious cause. Haemorrhage has been stemmed, transfusions have been given to correct shock and ample morphine has relieved thew sharp edge of pain. The sedated patient lies quietly into bed and his shallow paradoxical movements escape critical notice. But death steps in suddenly, peaces fully, naturally and unnecessarily.' Respiratory failures following a chest injury is a good example of a reversible breakdown in the mechanisms of breathing and if this vital function can be adequately substio tuted for a short period, complete recovery can beexpected (Ambiavagar et al., 1966). Particularo emphasis will therefore be placed on describing these relatively obscure processes in terms of currentlyo acceptable concepts of respiratory failure.

The complex disturbances of physiology are dueo to interference with: (1) the bellows action of the chest wall because of loss of rigidity and uniformity,, and reflex splinting due to pain; (2) 'alveolar $\overrightarrow{\vec{A}}$ capillary block' from pulmonary oedema; (3) diffuses reversible 'airways obstruction' (Ciba Foundation Symposium, 1959) from retained bronchial secre? tions; (4) atelectasis (Pasteur, 1914) and lung infec=을 tions; and (5) perfusion of unventilated areas of 3 . contused lung (Ambiavagar et al., 1966).

\section{Pathophysiology}

Injuries to the chest wall may or may not be associated with lung injuries. Some of the most extensive chest wall injuries in the patients we treated showed no lung contusion and, conversely, lung. contusions so severe that gas exchange was impossibles sometimes showed no rib fractures. Fig. 1 is a chest $\mathrm{X}$-ray from an 18-year-old boy admitted with massive haemoptysis following a road traffic accident. There were no rib fractures but respiratory failure was gross and hypoxaemia and hypercarbia을 persisted despite mechanical hyperventilation with pure oxygen. The patient died within $48 \mathrm{hr}$. This ${ }^{+}$ lack of correlation between lung and chest wall injury has been observed in other series as well (Wester-mark, 1941; William \& Bonte, 1962). Extensive $\frac{\stackrel{\rho}{\overparen{D}}}{\mathbb{Q}}$ contusions are fortunately uncommon but smaller $\mathbb{\Omega}$ contusions occur frequently and their radiologicalo appearances resemble those of atelectasis or con- $\Omega$ 
solidation. These usually heal in about 5 days and during IPPV with oxygen adequate $\mathrm{CO}_{2}$ removal is possible but large alveolar-arterial oxygen tension gradients are present (Table 2) and decrease as healing

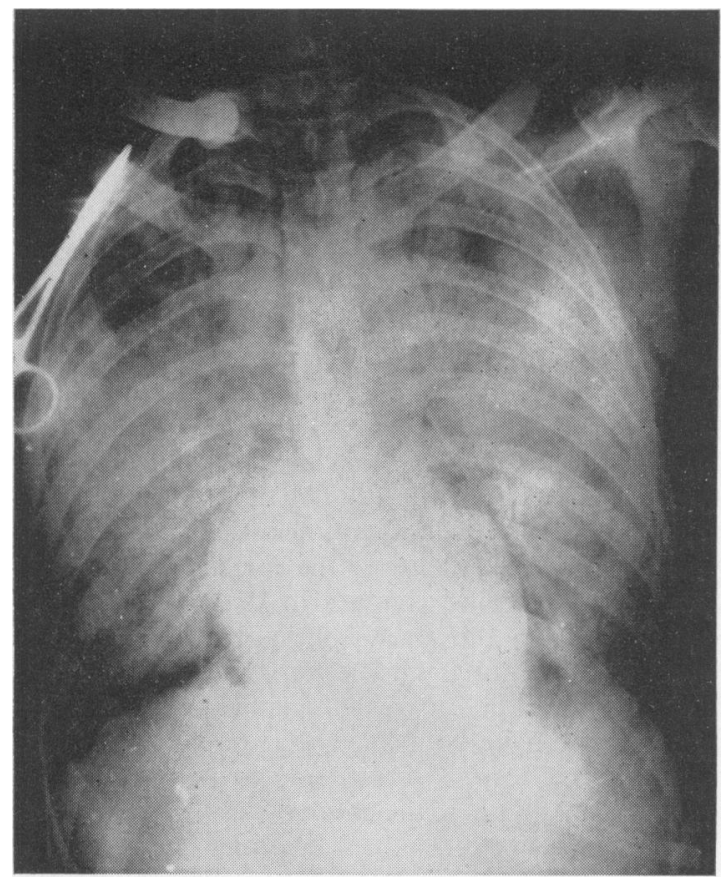

Fig. 1. Chest X-ray from an 18-year-old boy with massive haemoptysis following a road traffic accident.

takes place. Such pulmonary contusions may contribute to 'wetness' of the lungs following trauma to the chest but the characteristic 'wet lung' is a distinct entity.

\section{'Traumatic wet lung'}

Extensive experience with chest injuries during the Second World War resulted in descriptions of an audible wetness of the lungs due to increased bronchial secretions and lung oedema which these battle casualties were unable to clear by coughing. Burford \& Burbank (1945) described the condition in the words 'this all-important common denominator (of all chest injuries) exists and must be recognized'. U.S. army surgeons considered that 'no more serious problem was encountered by surgeons in Forward Hospitals treating thoracic wounds than the therapeutic problem of wet lung', which they defined as a persistence of fluid in the pulmonary tree which may be present in various forms-mucus, blood, serum, etc. Wet lung has been produced experimentally by trauma to the chest (Daniel \& Cate, 1948) and the literature on lung oedema has been reviewed by Visscher, Haddy \& Stephens (1956). In a thoughtful review of the subject, Harley (1961) concluded that mechanical, haemodynamic and neurogenic factors caused increased bronchial secretions with a reduced ability to expel them, increased the permeability of alveolar capillaries and disturbed the ventilation-perfusion ratio of the lungs. The evidence leading to these conclusions is somewhat fragmentary but the main point $I$ wish to make is that 'traumatic wet lung' was not seen during IPPV (Ambiavagar et al., 1966), and Griffiths (1960) observed that two of his patients who died during treatment with IPPV showed no evidence of wet lung at autopsy. One patient we treated was admitted $48 \mathrm{hr}$ after he had sustained fractures of five right ribs in a traffic accident. He was in respiratory failure with traumatic wet lung, consolidation and collapse of the left lung (Fig. 2). Following bronchoscopic clearance of the airways under general anaesthesia, the left main bronchus was intubated with a cuffed tube, the lung was manually reinflated and IPPV was maintained for 3 days. The second $\mathrm{X}$-ray was taken immediately after bronchoscopy and the patient had no recurrence of this syndrome. Re-expansion of atelectasis leads to immediate improvement in arterial oxygenation because perfusion of an unventilated area of lung leads to

TABLE 2

Effects of extensive lung contusions on gaseous homeostasis

\begin{tabular}{|c|c|c|c|c|c|c|c|}
\hline \multicolumn{2}{|c|}{ Patient } & \multirow{2}{*}{$\begin{array}{c}\text { Ventilator } \\
\text { East Radcliffe }\end{array}$} & \multirow{2}{*}{$\begin{array}{c}\begin{array}{c}\text { Airway } \\
\text { pressure } \\
\left(\mathrm{cmH}_{2} \mathrm{O}\right)\end{array} \\
25\end{array}$} & \multirow{2}{*}{$\begin{array}{c}\begin{array}{c}\text { Minute } \\
\text { volume } \\
(1 .)\end{array} \\
20\end{array}$} & \multirow{2}{*}{$\begin{array}{c}\begin{array}{c}\text { Arterial } \\
\mathrm{PCO}_{2} \\
(\mathrm{mmHg})\end{array} \\
26\end{array}$} & \multirow{2}{*}{$\begin{array}{c}\begin{array}{c}\text { Arterial } \\
\mathrm{Po}_{2} \\
(\mathrm{mmHg})\end{array} \\
187\end{array}$} & \multirow{2}{*}{$\begin{array}{l}\mathrm{A}-\mathrm{a} \\
\mathrm{Do}_{2} \\
497\end{array}$} \\
\hline J.H. & $\mathbf{R}$ & & & & & & \\
\hline E.C. & D & East Radcliffe & 18 & 24 & 20 & 90 & 600 \\
\hline G.S. & D & Cape & 24 & 26 & 20 & 100 & 590 \\
\hline T.T. & D & East Radcliffe & 25 & 15 & 55 & 87 & 568 \\
\hline T.G. & $\mathbf{R}$ & Bird Mark 8 & 20 & 17 & 29 & 123 & 560 \\
\hline T.H. & D & Cape & 30 & 18 & 30 & 65 & 605 \\
\hline
\end{tabular}

Inspired oxygen concentration in all cases was $100 \%$, ideal. Alveolar oxygen tensions were calculated on the assumption that $\mathrm{PACO}_{2}=\mathrm{PaCO}_{2}$.

$\mathrm{PaCO}_{2}$ was below normal in all except one patient but despite ventilation with pure oxygen, $\mathrm{PaO}_{2}$ remained low and the alveolar-arterial oxygen tension gradient was large (Ambiavagar et al., Thorax 1966). 
arterial desaturation (Berglund, Simonsson \& Birath, 1961).

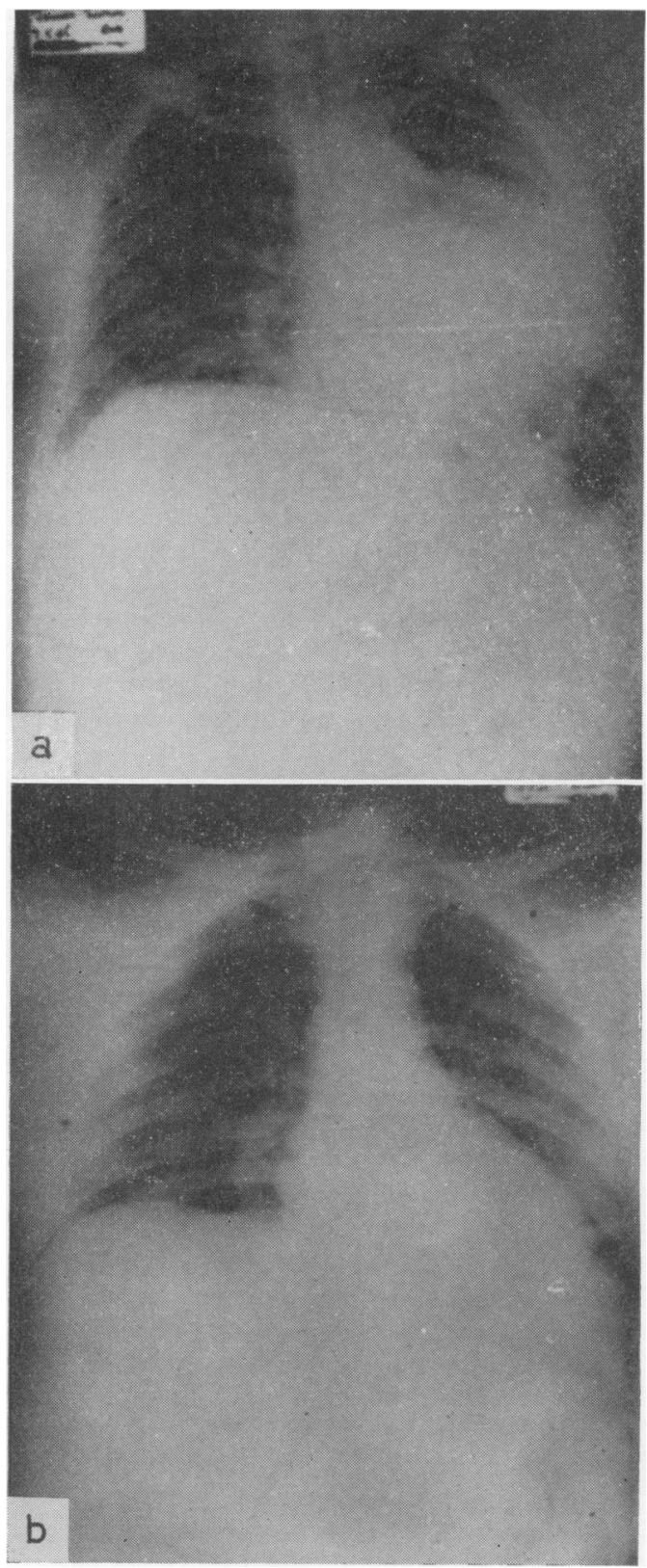

Fig. 2. (a) X-ray of patient admitted $48 \mathrm{hr}$ after sustaining fractures of five right ribs in a traffic accident. (b) X-ray taken immediately after bronchoscopy.

Flail chest and paradoxical respiration may result from rib and sternal fractures or from costo-chondral separations that are not visible on X-rays.

The latter injury is worth considering and was graphically described by Gordon Bryan in a Hunterian lecture (1921) in the words 'at the age of

18 it was my fortune to be run over by a motor bus, $\stackrel{\frac{1}{2}}{\frac{2}{2}}$ weighing about 2 tons and containing six people, $\stackrel{c}{.}$ the back wheel passing over the right hypochondrium $\overrightarrow{\vec{F}}$ and lower chest and the left shoulder. After the $\frac{\vec{\sigma}}{\circ}$ accident, no lesion was discoverable until the right $\frac{}{\circ}$ side of the chest wall fell in 3 days later as a result $\frac{\bar{c}}{\bar{c}}$ of separation of the attachments of the right costal $\frac{\nabla}{\phi}$ cartilages.' The physiologic deficit in paradoxical $\propto$ respiration is usually ascribed to mobility of the mediastinum and 'pendelluft'-the movement of $\vec{\circ}$ residual air from one lung to the other (Edwards, $\vec{\overrightarrow{ }}$ 1966). No studies are available on what does happen $\vec{\rho}$ when flail segments occur after injury, but studies $\frac{}{0}$ following surgical thoracoplasties have shown that $\frac{0}{3}$ alveolar ventilation is decreased and venous admixture in left arterial blood is increased (Stead \& $\omega$ Soucheray, 1952). Maloney, Schmutzer \& Raschke $\overrightarrow{0}$ (1961) (Fig. 3) sampled carinal gases continuously in experimental animals with flail chest and found no or increase of $\mathrm{CO}_{2}$ during inspiration as would occur 0 if residual air moved across the carina. Further, the intrapleural pressure changes in the flail side were $\rightarrow$ identical with those during normal breathing, indicating that lung volume was increasing during inspiration. Studies of carinal gas flows by pneumo- $\mathscr{\mathscr { S }}$ tachography have confirmed that no air-flow from the damaged to the sound side is present during inspiration. Whatever the cause of respiratory failure in paradoxical respiration, it has long been appreciated that IPPV is adequate therapy (Brauer, 1932).

Traumatic thoracoplasty, which may be a late $\stackrel{\perp}{\circ}$ result of inadequate treatment of a flail chest, leaves $\overrightarrow{\overrightarrow{0}}$ a permanent deformity and disability and can occur 3 despite stabilizing operations because ribs move $\bar{P}$ constantly and effective fixation is difficult under these conditions. The deformity impairs the functional contribution of the affected lung (Watson \& Gaensler, 1952) and causes irreversible reduction in function of the opposite hemithorax by the mechanical effects of abnormal muscle pull and rotoscoliosis (Gaensler \& Strieder, 1951).

Whatever the cause of respiratory failure following a chest injury and regardless of whether it is present from the time of injury or develops later, the single most important procedure in its treatment is endotracheal intubation. If severe respiratory failure is present from the outset and is associated $N$ with a head injury and an unstable chest wall, this procedure must take precedence over all others. Where the patient is conscious, anaesthesia is induced $\bullet$ with a small dose of thiopentone, and intubation follows the injection of a small dose of suxamethonium. Ventilation is then manually controlled with a reservoir bag and oxygen, and this procedure should be within the capability of the first doctor to see the patient. If respiratory failure is not so severe as to threaten life immediately, it is preferable to commence blood transfusion and assess the 


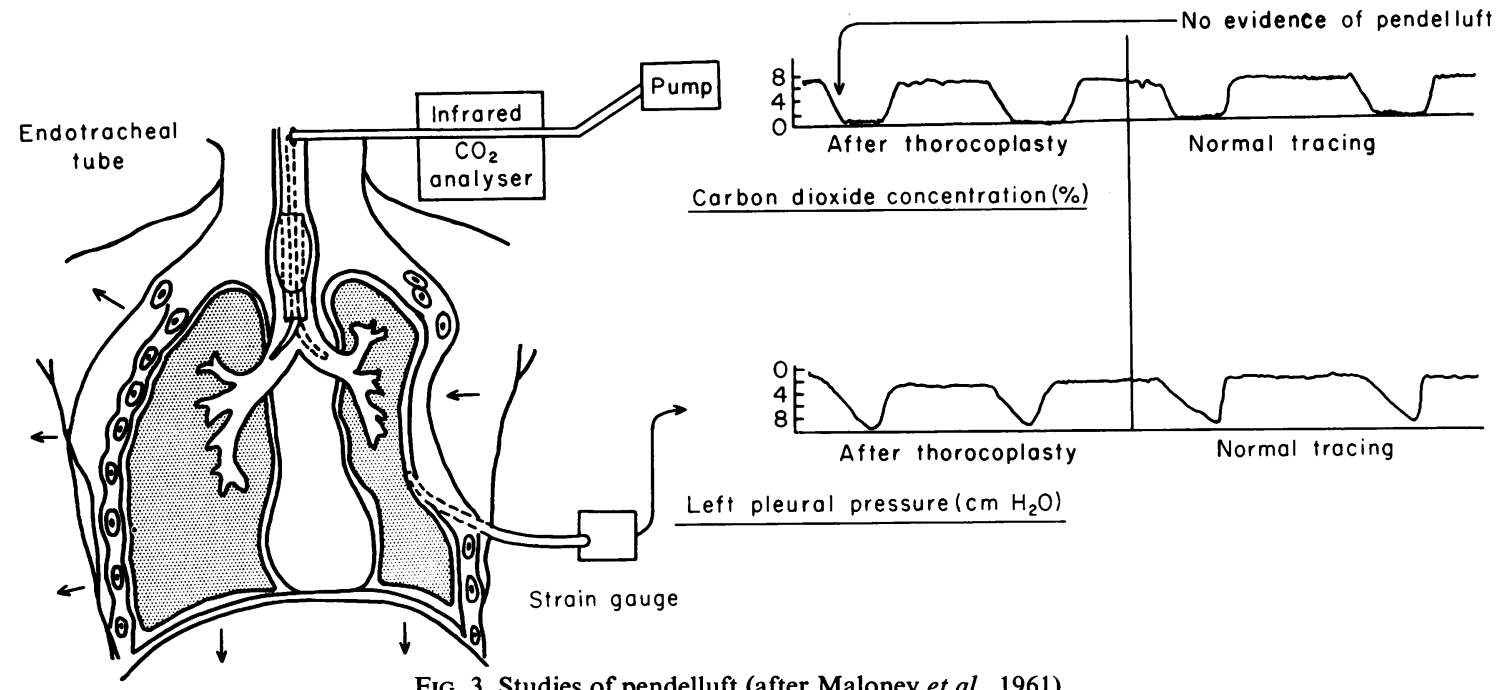

Fig. 3. Studies of pendelluft (after Maloney et al., 1961).

extent of injury as thoroughly as possible before commencing treatment. Neurological damage and blood loss should be carefully assessed and damage to the viscera, particularly those in the upper abdomen, diagnosed. Antero-posterior and lateral radiographs of the chest are essential and the lateral film should be carefully examined for mediastinal emphysema which may indicate a tear in the tracheobronchial tree. This injury is not uncommon (Mahaffey et al., 1956) and is of particular importance if IPPV is to be used, as rapid fatal tension pneumomediastinum may result. As clinical and radiological methods may be inadequate to diagnose this condition, it is our practice to precede intubation with bronchoscopy. The other, not so obvious, injury that must be excluded is diaphragmatic rupture, which is common following crushing violence to the chest (Bryan, 1921). During IPPV no clinical signs result from such an injury but there is an everpresent danger of herniation of a small segment of bowel through the tear resulting in intestinal obstruction or strangulation.

When injuries requiring surgery are present, the anaesthetic used for intubation is continued with DTC, nitrous oxide and oxygen, and IPPV and the patient is taken to the operating theatre. When the necessary surgery has been completed, tracheostomy is performed prior to transfer to the intensive care unit.

\section{The tracheostomy}

There is no place in hospital practice for 'kitchenknife tracheostomies' and very little place for them anywhere. Under poor conditions, the operation itself carries a mortality and an even greater morbidity. Tracheostomies are performed under aseptic conditions with endotracheal intubation and con- trolled ventilation. I am convinced that controlled ventilation is necessary because the operation involves opening tissue planes in the neck through which air can be drawn into the mediastinum during inspiration, particularly if abnormally large intrapleural pressures are present as a result of increased resistance to breathing, and also because curarization ensures a perfect operating field by preventing coughing during the manipulations. Bleeding at the site is thus reduced to a minimum. A vertical skin incision is preferred because the upper edges of horizontal incisions become oedematous during prolonged IPPV, making the changing of tracheostomy tubes difficult. For the same reason, tracheal fenestration is necessary and we use high tracheostomies, avoid cutting the first tracheal ring and keep the transverse diameter of the window smaller than one-third the diameter of the trachea.

\section{Care of the tracheostomy}

We change tracheostomy tubes daily and as the main danger with a tracheostomy is 'hospital fever', strict aseptic precautions are observed during nursing (Fig. 4). Sucking out a tracheostomy in itself increases bronchial secretions and we try and avoid the procedure unless necessary. Endobronchial suction is carried out by a nurse wearing a sterile gown and glove, and a mask. The stiff, angulated Pinkerton catheters, which are necessary if the left main bronchus is to be entered and cleared, are separately packaged in nylon envelopes and autoclaved. The ends of the envelope are cut off immediately prior to use and the operator then extrudes the end of the catheter without touching it, disconnects the ventilator with the sterile glove and introduces the catheter.

Samples of bronchial secretion obtained in a 
mucus trap are cultured every other day and the antibiotic sensitivity of the organism is determined. In addition the tracheostome is sprayed daily with polybactrin and nystatin as wound infections from airborne droplets spread rapidly down the tracheobronchial tree. If secretions become thick and difficult to remove, $5-10 \mathrm{ml}$ of sterile saline warmed to body temperature are instilled into the tracheostomy tube periodically.

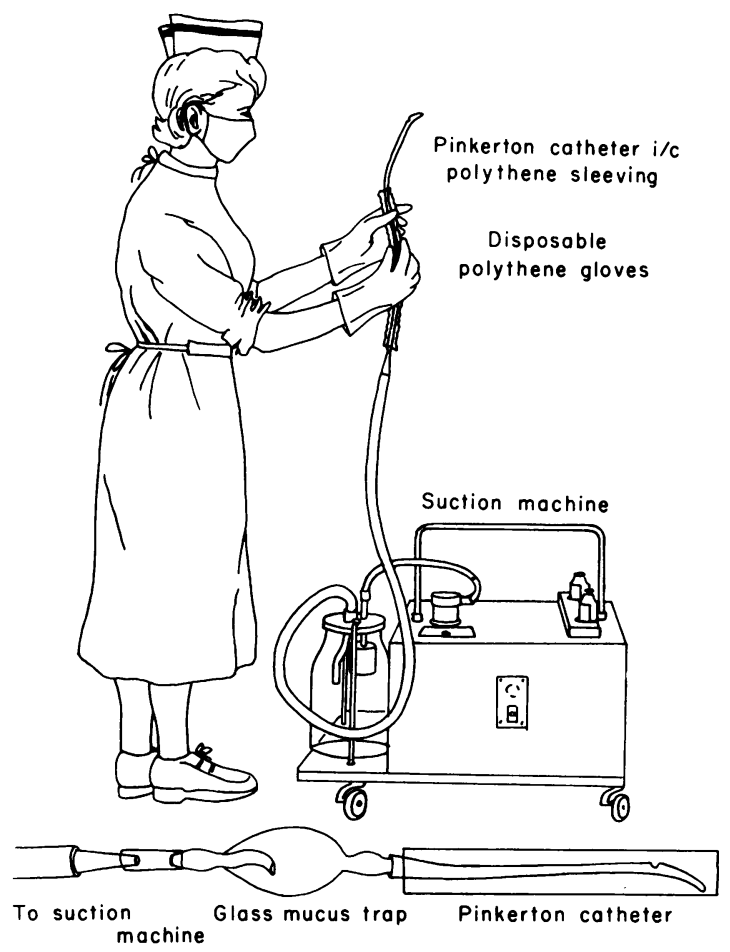

FIG. 4. Tracheostomy care.

This dissertation on tracheostomies may seem disproportionately long, but I consider it the most important single operation in the treatment of chest injuries, and its care, the most important nursing procedure.

\section{Management of prolonged IPPV}

If flail segments are present, complete control of ventilation is maintained by over-ventilating the lungs to produce a mild respiratory alkalosis. A negative phase is not used because it causes indrawing of the fracture sites and triggering of the machine or fighting the ventilator must be avoided. The objective is to expand the lungs passively from within so that the broken bones lie on a surface that is rising and falling gently thereby preventing movement of the broken bone-ends on each other and ensuring immobilization of the fracture sites. As the lungs never decrease beyond the end-expiratory position, the thoracic cage heals in optimal position. The fracture sites become sticky enough in 6-8 days $C$. for the patient to breathe spontaneously, even though no callus is visible on X-rays. In the absence of flail segments, tracheostomy, endobronchial suction and assisted ventilation are adequate therapy.

Fig. 5 summarizes the principal features of $\overrightarrow{\vec{D}}$ ventilator treatment. The patients are nursed with $\varrho$ the trunk inclined at $30^{\circ}$ to the horizontal and fed $\nRightarrow$ via a nasogastric tube with a Complan-glucose $\overrightarrow{0}$ mixture as Dr Peaston will be describing tomorrow, unless intragastric feeding is contra-indicated for $\vec{\omega}$ some reason. In this case, amino acids, fats, sugars, electrolytes and fluids are given intravenously. Blood transfusion is often required in addition. The bladder is catheterized and urine output is charted $\vec{\omega}$ hourly. By this means, external balances of fluid and nitrogen are maintained.

In addition, the nursing staff are expected to monitor body temperature, pulse rate and blood pressure, watch the manometer on the ventilator and carry out other routine procedures such as physiotherapy, treatment of pressure areas and maintenance of equipment. For these reasons, specialist training is required and their task is reduced to manageable proportions by the keeping of charts.

Adequacy of ventilation is assessed by the clinical condition of the patient, the chest X-rays and estimation of arterial blood gas tensions. If a patient begins to fight the ventilator, it is assumed that ventilation is inadequate and the cause is sought and eliminated. Antero-posterior X-rays of the chest are taken daily for the first 3 days and on the 5th, 7th and 9th days and on the day of discharge. Additional X-rays and special views may occasionally be required.

The complications of IPPV we encountered were atelectasis, which responded to bronchoscopy and manual reinflation as I described previously, hospital cross-infection of the tracheostomy with Ps. pyocyanea in one case which proved fatal, pneumothorax in one patient, and systemic hypotension which always responded to blood transfusion.

\section{Choice of ventilator}

We have used a Cape Barnet, East-Radcliffe and Bird with equal success (Table 3 ). Any quiet reliable machine that can produce minute volumes of $\tilde{\omega}$ 25 litres with a Type III flow pattern is suitable. The machine need not incorporate a triggering device or negative phase.

\section{Termination of mechanical ventilation}

Mechanical ventilation was terminated when there was no arterial hypoxaemia during IPPV with air, the chest X-ray was normal, and the patient was able to breathe deeply and cough effectively without much pain. If paradox was minimal or absent at 


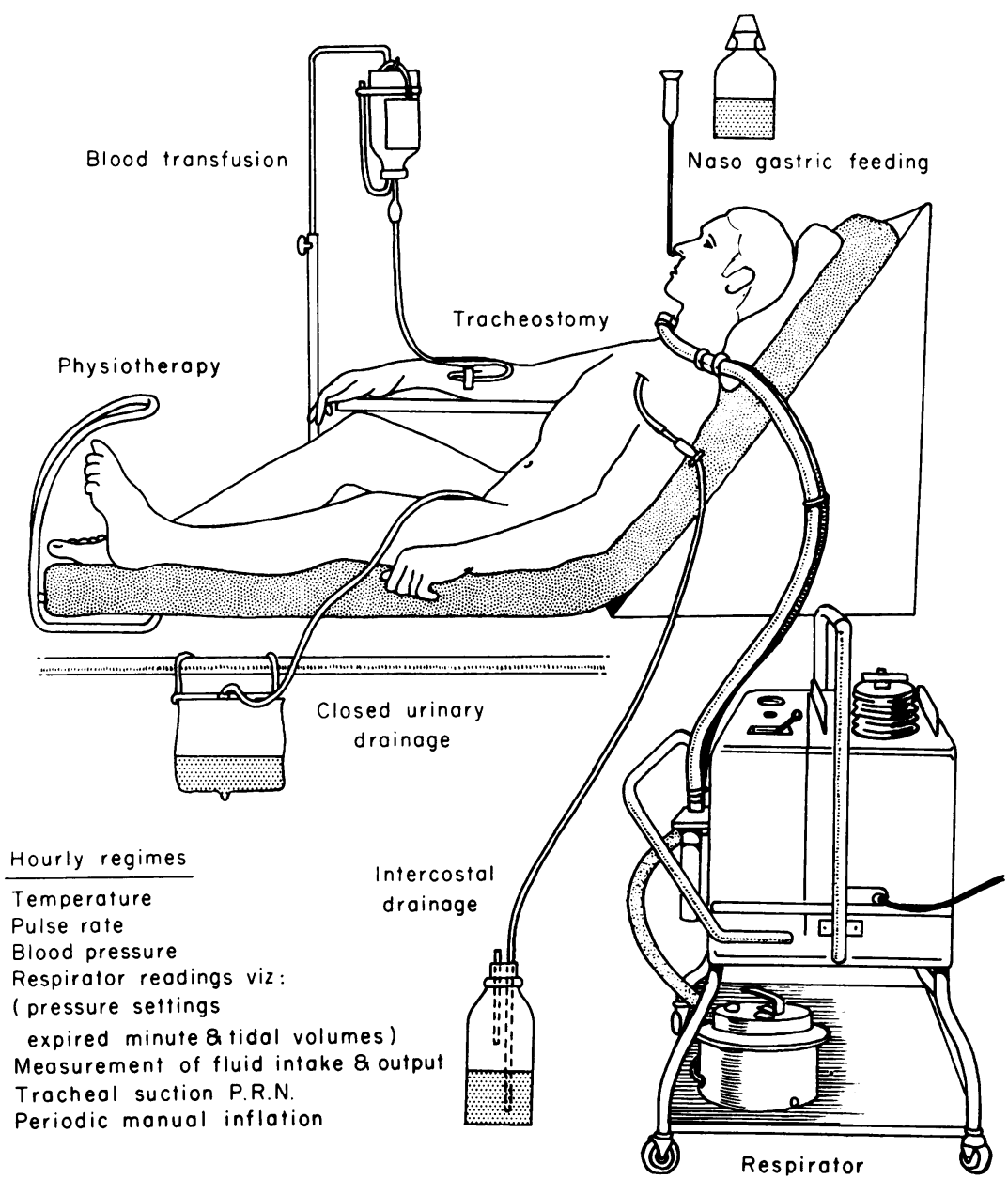

FIG. 5. Essential features of treatment by IPPV.

this stage, the patient was allowed to trigger a Bird ventilator for $48 \mathrm{hr}$ with short periods of spontaneous respiration. If the patient maintained satisfactory

TABLE 3

Efficiency of ventilators used

\begin{tabular}{lrccc}
\hline Ventilator & $\begin{array}{c}\text { No. } \\
\text { of } \\
\text { cases }\end{array}$ & $\begin{array}{c}\text { Airway } \\
\text { pressures } \\
\text { used } \\
\left(\mathrm{cmH} \mathrm{H}_{2} \mathrm{O}\right)\end{array}$ & $\begin{array}{c}\text { Arterial } \\
\mathrm{PcO}_{2} \\
<30 \mathrm{mmHg}^{2} \\
\text { (No. of } \\
\text { cases) }\end{array}$ & $\begin{array}{c}\text { Arterial } \\
\mathrm{Po}_{2}>80 \\
\mathrm{mmHg} \\
\text { (No. of } \\
\text { cases) }\end{array}$ \\
\hline East-Radcliffe & 11 & $15-30$ & 10 & 9 \\
Cape & 3 & $20-30$ & 3 & 2 \\
Bird Mark 8 & 2 & $15-20$ & 2 & 2 \\
\hline
\end{tabular}

progress during this time, ventilation was discontinued, and the cuffed Radcliffe tracheostomy tube was replaced with a silver speaking tube. After $24 \mathrm{hr}$ this was removed and the tracheostome was covered with a sterile pad and allowed to close spontaneously.

In conclusion, it must be pointed out, a large number of patients with minor chest trauma never go into respiratory failure, but it is seldom possible to predict with certainty which patients will. It is known that patients with concomitant head injuries (Schrire, 1962), slowly developing haemothorax (D'Abreu, 1965) and pre-existing lung disease (Ambiavagar et al., 1966) are particularly liable to this fate following minor chest trauma.

The outlook is more serious with anterior flail segments than with posterior flail segments of a comparable size, because respiratory excursions are normally smaller over the back and because the scapulae and great muscles of the back act as splints. Similarly, fractures of the lower ribs, particularly those to which the diaphragm is attached, are more dangerous than an equal number of upper rib fractures, but it is, in the main, impossible to predict 
the outcome from the number of broken ribs, the age of the patient or the clinical condition on admission.

The number of patients with minor injuries who develop respiratory failure can be reduced if they are vigilantly nursed, pain is controlled by the judicious use of analgesia, adequate physiotherapy is carried out, appropriate antibiotics are administered and adequate nutrition is maintained. Dehydration, in particular, must be prevented as it causes inspissation of bronchial secretions and increases the difficulty of expectoration. An adequate fluid intake is therefore important. If, despite these measures, the patient is unable to cough effectively enough, and there is continuing and increasing dyspnoea, analysis of arterial blood gas tensions may show hypoxaemia and hypercapnia severe enough to justify more drastic measures. Mental confusion and coma are late signs of respiratory failure and should be anticipated in every instance.

\section{References}

Ambiavagar, M., Robinson, J.S., Morrison, I.M. \& Jones, E.S. (1966) Intermittent positive pressure ventilation in the treatment of severe crushing injuries of the chest. Thorax, 21, 359.

Avery, E.E., Mörch, E.T. \& Benson, D.W. (1956) Critically crushed chests; a new method of treatment with continuous mechanical hyperventilation to produce alkalotic apnea and internal pneumatic stabilization. J. thorac. Surg. 32, 291.

BARRETt, N.R. (1960) The stove-in-chest. Lancet, i, 293.

Berglund, E., Simonsson, B. \& Birath, G. (1961) Effect of induced pneumothorax on the pulmonary shunt and the ventilation in a patient with atelectasis of the lung. Amer. J. Med. 31, 959.

Boyle, A.K., Gallie, J.R. \& Murray, D.B. (1957) Crush injury of the chest. Anaesthesia, 12, 453.

BRAUER, L. (1932). Die respiratorische Insuffizienz. Verhandl. deut. Ges. inn. Med. 44th Congress, p. 120.

Brewer, L.A., Burbank, B., Samson, P.C. \& Schiff, C.A. (1946) The 'wet lung' in war casualties. Ann. Surg. 123, 343.

BRYAN, C.W.G. (1921) Injuries of the diaphragm: with special reference to abdominothoracic wounds. Brit. J. Surg. 9, 117.

Burford, T.H. \& Burbank, B. (1945) Traumatic wet lung. J. thorac. Surg. 14, 415.

CARTER, B.N. \& GiUsefFi, J. (1951) Tracheotomy, a useful procedure in thoracic surgery, with particular reference to its employment in crushing injuries of the thorax. $J$. thorac. Surg. 21, 495.

Ciba Foundation Symposium (1959) Thorax, 14, 286.

Cournand, A. \& Richards, D.W. (1941) Pulmonary insufficiency. II. The effects of various types of collapse therapy upon cardiopulmonary function. Amer. Rev. Tuberc. 44, 123.

D'ABReu, A.L. (1965) Thoracic injuries. J. Bone Jt Surg. 46B, 581.
DANiel, R.A., JR \& CARE, W.R., JR (1948) 'Wet Lung', an experimental study. Ann Surg. 127, 836.

EDWARDS, F.R. (1966) Foundations of Thoracic Surgery, p. 28. Livingstone, Edinburgh.

Fairley, H.B. \& Chambers, R.A. (1960) The management of the patient with respiratory insufficiency. Canad. Anaesth. Soc. J. 7, 447.

Gaensler, E.A. \& Strieder, J.W. (1951) Progressive changes in pulmonary function after pneumonectomy. The influence of thoracoplasty, pneumothorax, oleothorax and plastic sponge plombage on the side of the pneumonectomy. J. thorac. Surg. 22, 1.

Gaensler, E.A., Watson, T.R. \& Patton, W.E. (1953) Bronchospirometry. VI. Results of 1089 examinations. J. Lab. clin. Med. 41, 436.

Gothman, B. \& Hogman, L. (1964) Current treatment of acute thoracic injuries. Acta chir. scand. 127, 609.

GRIFFITHS, H.W.C. (1960) Crush injuries of the chest. J. roy. Coll. Surg. Edinb. 6, 13.

Griffiths, H.W.C. (1963) Stove-in-chest. Lancet, i, 1108.

HARLEY, H.R.S. (1961) Discussion on non-penetrating injuries of the chest and abdomen. Proc. roy. Soc. Med. $54,558$.

JACOBEUS, H.C. (1938) Bronchospirometry. J. thorac. Surg. $7,235$.

Johansson, L. \& Silander, T. (1959) Twenty-one years of thoracic injuries. Acta chir. scand. Suppl. 245, 91.

Lloyd, J.W., Crampton-Smith, A. \& O'Connor, B.T. (1964) Classification chest injuries as an aid to treatment. Brit. med.J. i, 1518.

London, P.S. (1963) Multiple injuries. Proc. roy. Soc. Med. 56, 821.

Mahaffey, D.E., Creech, O., JR, Boren, H.G. \& DeBaKey, M.E. (1956) Traumatic rupture of the left-main bronchus successfully repaired eleven years after injury. $J$. thorac. Surg. 32, 312.

Maloney, J.V., Schmutzer, K.J. \& Raschke, E. (1961) Paradoxical respiration and 'Pendelluft'. $J$. thorac. cardiovasc. Surg. 41, 291.

Nordlund, S. (1966) Personal communication.

Pasteur, W. (1914) Massive collapse of the lung. Brit. J. Surg. 1, 587.

SCHRIRE, T. (1962) The comatose injured patient. S. Afr. med. J. 36, 747.

Stead, W.W. \& Soucheray, P.H. (1952) Physiologic studies following thoracic surgery. I. Immediate effects of thoracoplasty. J. thorac. Surg. 23, 453.

Visscher, M.B., Haddy, F.J. \& Stephens, G. (1956) Physiology and pharmacology of lung edema. Pharmacol. Rev. 8, 389.

WATSON, T.R., JR \& GAENSLER, E.A. (1952) Immediate and late respiratory impairment due to selective stages thoracoplasty, extraperiosteal plombage and extrapleural conversion thoracoplasty. Trans. nat. Tuberc. Ass. 48,

WestermarK, N. (1941) Roentgenological investigation into traumatic lung changes arisen through blunt violence to the thorax. Acta radiol. (Stockh.), 22, 331.

Whitwam, J.G. \& NoRman J. (1964) Hypoxaemia after crush injury of the chest. Brit. med. J. i, 349.

Williams, J.R. \& BonTe, F.J. (1962) Pulmonary hematomas secondary to nonpenetrating injury. Sth. med. J. (Bgham, Ala.), 55, 622.

Williams, W.G. \& Zeitlin, G.L. (1965) The management of flail chest. Brit. J. Dis. Chest, 59, 15.

WinDSOR, H.M. \& DWYER, B. (1961) The crushed chest. Thorax, 16, 3. 